\title{
Pitfalls in the Cytological Assessment of Thyroid Nodules
}

\author{
Şule CANBERK' ${ }^{1}$, PInar FIRAT ${ }^{2}$, Fernando SCHMITT ${ }^{3,4}$
}

Department of Pathology, ' Haydarpasa Numune Education and Research Hospital, ISTANBUL, TURKEY, ${ }^{2}$ stanbul University, Istanbul Faculty of Medicine, ISTANBUL, TURKEY, ${ }^{3}$ Department of Pathology and Medicine, Laboratoire National de Sante, LUXEMBOURG

${ }^{4}$ Instituto de Patologia e Imunologia Molecular da Universidade do Porto (IPATIMUP), PORTO, PORTUGAL

\begin{abstract}
Fine needle aspiration of thyroid has been used for years in a multidisciplinary approach, to diagnose different entities, in preventing over or under treatment of thyroid nodules. The widespread use of this methodology can be confirmed if "thyroid fine needle aspiration" is searched on PubMed, which results in over 5000 papers. In this manuscript, we aimed to focus on pitfalls in the evaluation of thyroid aspirations, covering cystic, inflammatory lesions, follicular lesions, oncocytic lesions, papillary carcinoma, and medullary carcinoma of thyroid.
\end{abstract}

Key Words: Thyroid, Fine needle aspiration, Cytology, Thyroid nodule, Thyroid cancer

\section{INTRODUCTION}

Sampling thyroid by using needles is one of the oldest diagnostic techniques in the medical history known since 936-1013AD as written in the book of Abu al-Qasim (1). Thyroid nodules are common, and can be detected from $4-7 \%$ up to $50-70 \%$ by the increased usage of high resolution ultrasonography. Most of them are benign; only 5-15\% are malignant $(2,3)$. Even after the development of advanced radiologic and molecular techniques, fine needle aspiration (FNA) still stands as the cornerstone of the diagnostic approach. It is a well-accepted, widely used, minimally invasive, cost effective technique with high sensitivity and specificity (4).

This manuscript aimed to cover pitfalls in the cytological diagnoses of cystic lesions, inflammatory conditions, follicular lesions, oncocytic (Hürthle cell) lesions, papillary carcinomas (PTC), and medullary carcinomas (MTC) of the thyroid.

\section{CYSTIC LESIONS}

Pitfalls in the evaluation of cystic lesions and hyperplastic nodules frequently cause diagnostic difficulty in our routine practise. Cysts in thyroid are common, and most of them are benign. However, malignant neoplasms may also present as cystic lesions.

\section{A. True Cysts}

Thyroglossal duct cysts, parathyroid cysts, epidermoid cysts, branchial cleft cysts can all occur either in thyroid or near thyroid (lateral midline cysts) (5). They may be called

(Turk Patoloji Derg 2015, 31(Suppl):18-33)

Received : 14.06.2015 Accepted : 16.06.2015 as "true cysts" of this area. The reported rate of parathyroid cysts is $0.6-3 \%$, thyroglossal cysts is $7 \%$ including paramidline localization (5-7). Depending on the sampling track or the nature of the lesion as in thyroglossal duct cyst, follicular epithelium can be observed in their aspirates and cause diagnostic difficulties (7). Ciliated cells, lymphocytes, squames, colloid, keratin are the components helping in the differential diagnosis $(5,6)$. Colorless or water-clear fluid mostly suggest parathyroid cysts, the others as well as thyroid cysts/ pseudocysts are characterized by yellowish to brown cyst contents $(5,8)$. The biochemical analysis of the cyst fluid has great value in differentiating parathyroid cysts from the others $(5,8)$. PTC associated with thyroglossal duct cyst is very rare but may cause a real challenge. Distinguishing thyroglossal duct cyst associated PTC from metastatic PTC in a lymph node is important but extremely difficult based only by morphology on cytology aspirates (7).

\section{B. Pseudocysts/ Hyperplastic Nodules}

The term "pseudocyst" is used to describe the cysts occurring due to internal or external changes in thyroid like cystic colloidal nodules, degenerative cysts lacking epithelial component, post-FNA reparative processes.

Hyperplastic nodules tend to undergo cystic/ degenerative/ reparative changes; haemorrhage, stromal fibrosis, hyalinization, necrosis and calcification may occur (3, 9). Large colloid pools may develop with total absence or atrophy of the epithelium. Then, the aspirates show foamy cells, hemosiderin-laden macrophages, proteinaceous

Correspondence: Fernando SCHMITT

Director of the Department of Pathology and Medicine,

Laboratoire National de Sante, 1, rue Louis Rech,

L-3555 DUDELANGE, LUXEMBOURG

E-mail: Fernando.schmitt@lns.etat.lu Phone: +352 28100340 
granular debris/ watery colloid, scarce amount of epithelium and fibroblasts (10-12). The reactive cyst lining cells have distinct cytoplasmic borders, loose to dense granular cytoplasm, occasional exaggerated unipolar/ bipolar cytoplasmic processes. Nuclei can be large, round to oval but always with regular borders, and may show grooves and hypochromasia with distinct nucleoli (10-12) (Figure 1AC).

Cystic changes and degenerative processes may cause florid atypia named by De May (5) as worrisome atypical cells of regenerative-degenerative processes (WARD cells) which is a significant cause of false positive and negative results (10-12). In a study on thyroid cysts containing atypical cells, among 12 selected cytological features, intranuclear pseudoinclusions, papillary microarchitecture, nuclear crowding and mitoses were the ones suggesting carcinoma (11).

Hyperplastic nodules typically show thyroid follicular epithelial cells with small, round, dark nuclei in honeycomb arrangement, follicles variable in size and/or single thyroid follicular epithelial cells embedded in abundant watery colloid. Cytoplasmic characteristics vary from scant to large, mildly vacuolated, plump with thyroglobulin blebs or oncocytic $(3,13)$. However, focal nuclear atypia including grooves, oval shape, chromatin clearing, and overlapping are reported in hyperplastic nodules causing diagnostic difficulties (14) (Figure 2A,B).

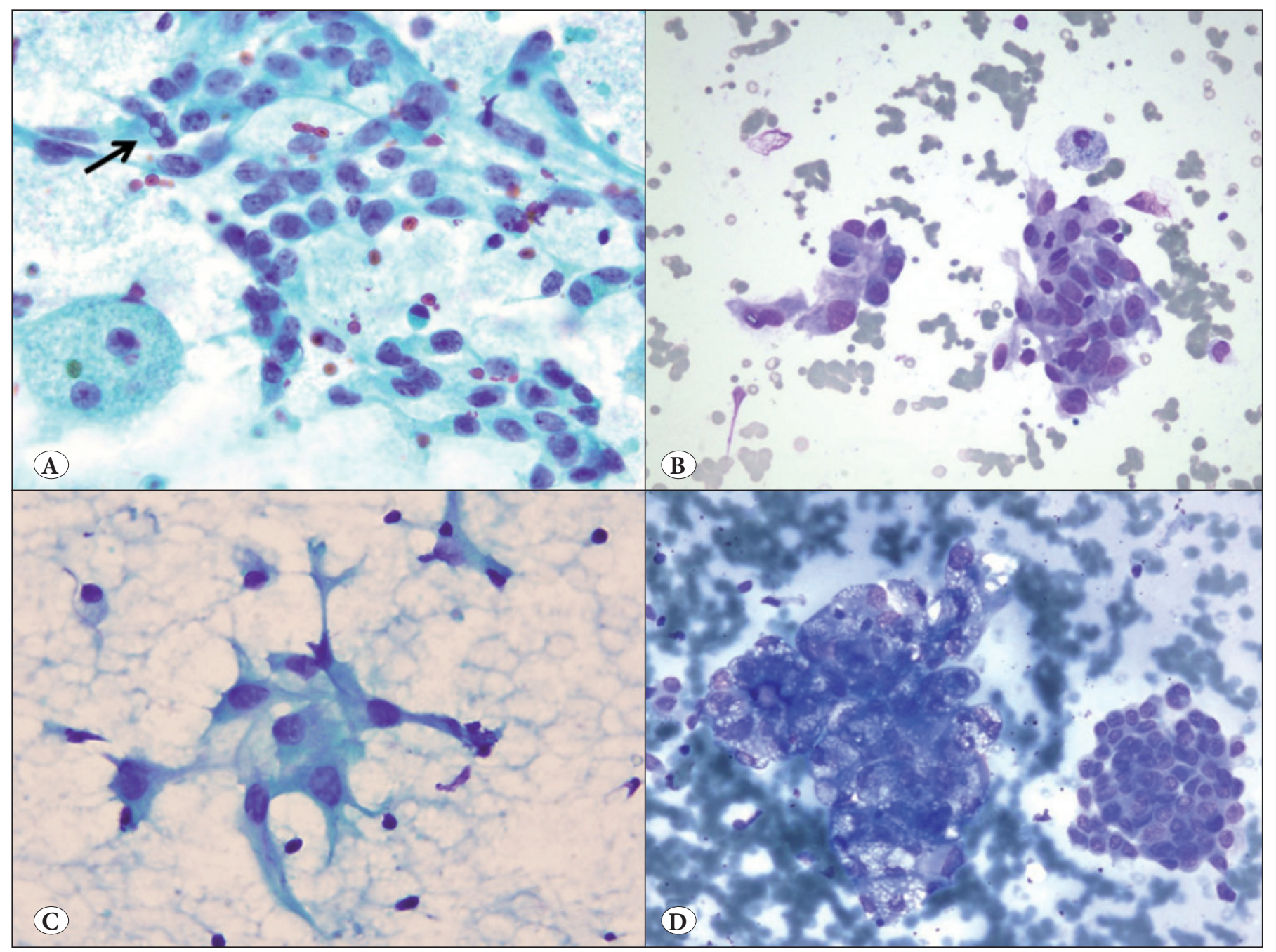

Figure 1: A) Reactive/reparative epithelial cells with large oval nuclei, fine chromatin, and small conspicious nucleoli showing a pseudoinclusion-like nuclear hole (arrow) and occasional grooves (Pap x1000). B) Groups of reactive epithelial cells from a cystic lesion with oval to elongated nuclei and dense cytoplasm (MGG x400). C) Exaggerated cytoplasmic processes in reactive/regenerative epithelial cells (Pap x1000). D) Cytoplasmic hypervacuolization in cystic papillary thyroid carcinoma causing an histiocytic appearance (MGG $\mathrm{x} 400)$. 
Besides atypia at cellular level, papillary formations or sampling from the microfollicule dominant areas may also cause diagnostic challenges based on pattern atypia $(3,13)$. Presence of abundant loose/ watery colloid can keep cytopathologist away from over-diagnosing, Still two scenarios - macrofollicular variant of PTC and cystic PTCshould always be remembered. Careful search for nuclear details is crucial.

Fine needle aspiration may lead worrisome changes in the histology of benign nodules which are first described by LiVolsi and Merino (15). Follicular cells along the FNAneedle track can demonstrate nuclear enlargement and marked nuclear clearing, which can be mistaken for PTC; in addition to nuclear atypia hemorrhage, inflammation and reactive stromal changes may develop. All these alterations may be reflected on repeat FNAs from these nodules, so atypical cells seen in FNAs from previously aspirated thyroid nodules should be evaluated with caution, especially if the time interval between the initial and repeat FNA is less than $8-12$ weeks $(3,16)$

\section{Malignancies with Cystic Component}

Follicular neoplasms, PTC and MTC may have cystic components, and aspirates from those cystic tumours usually yield hypocellular specimens causing false negative diagnosis $(10-12,17)$. Tumour cells in cyst fluids, especially cells from PTC may show cytoplasmic hypervacuolization and can be misinterpreted as macrophages (histiocytes) (13) (Figure 1D). If present, "bubble gum colloid" is a useful clue in the diagnosis of cystic PTC. Sticky colloid attached to vacuolated epithelial cells should elicit a careful search

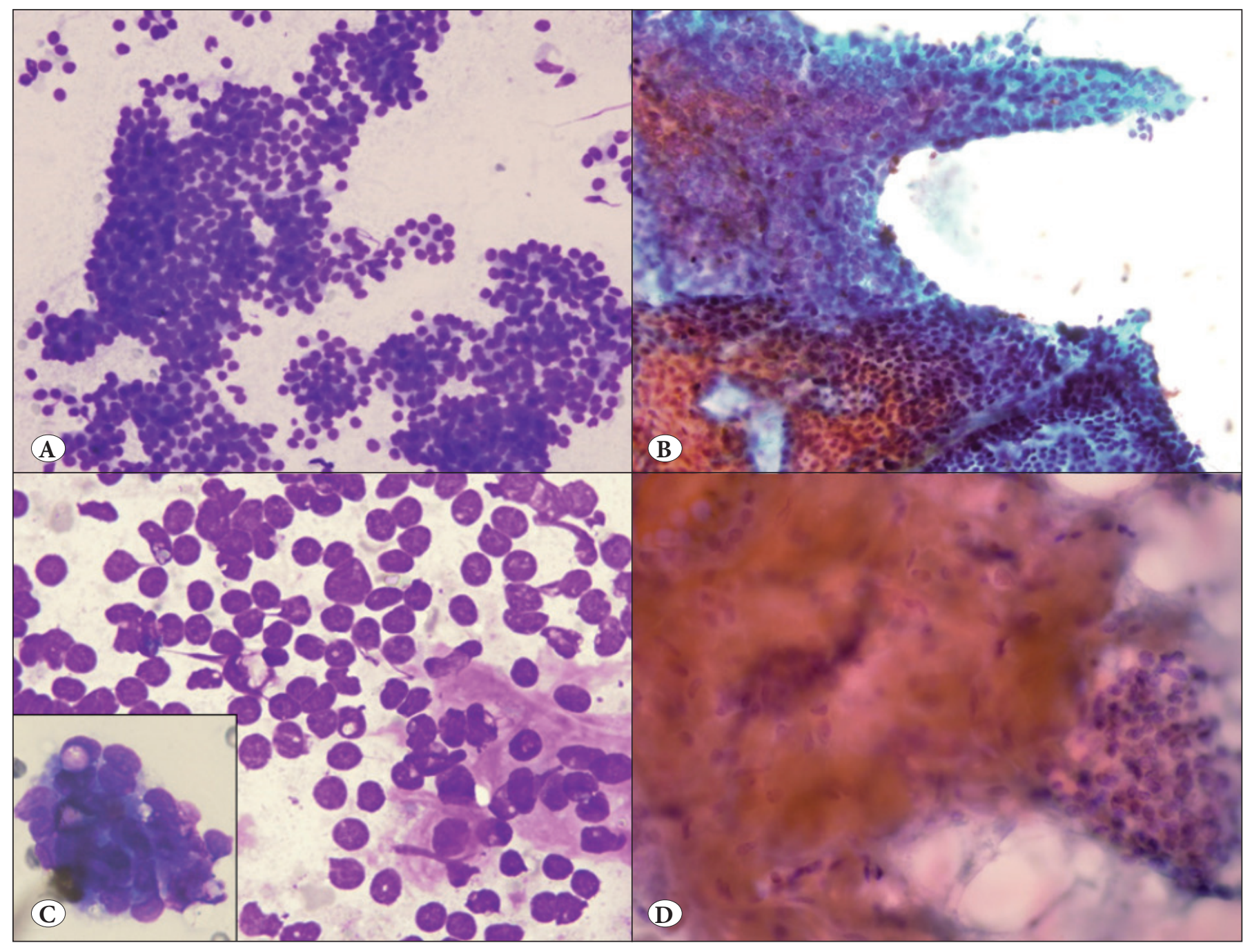

Figure 2: A,B) Hyperplastic nodules with pseudopapillary formations, some chromatin clearing and nuclear overlapping (MGG x200, Pap x200)]. C) Optically clear holes protruding out of the nuclear borders mimicking intranuclear pseudoinclusions (MGG x1000). D) Folliculer epithelial cells embedded in amorphous, dense, hyaline material, pink to orange in color from an amyloid goiter (Pap x400). 
for more cells with characteristic nuclear features of PTC in a cystic aspirate with low cellularity (13).

MTC rarely presents as a cystic lesion. Recognising the isolated or loosely grouped neoplastic cells in the cyst fluid may be challenging, and can be easily overlooked as macrophages and/or thyroid follicular epithelial cells with or without oncocytic change. MTC may also be associated with papillary formations mimicking PTC. Immunohistochemistry and/or serum calcitonin levels will help to solve the diagnostic dilemma in such cases $(17,18)$.

\section{GRAVES' DISEASE}

Graves' disease is a common cause of hyperthyroidism, and seen in $0.5 \%$ of the United States population. Reported rates of malignancy vary between $2.3-19 \%$ (19). Oncocytic and/ or non-oncocytic thyroid follicular epithelial cells, high amount of flame cells, watery colloid, lymphocytes, and rarely granulomas are seen in aspirations (20). Cytological findings are challenging, especially after treatment (21). Distinctive pleomorphism, hyperchromasia, elongation of nuclei with occasional grooves and inclusions can be seen in this benign entity (20-22). Even an experienced cytopathologist may easily be trapped by papillary structures showing nuclear features suspicious for PTC. "Complete" PTC cytomorphology should be taken in account to diagnose "PTC" in the background of Graves' disease (20).

\section{THERAPY EFFECTS}

Cytological atypia may occur in thyroid after radiation (radioactive iodine/ external radiation beam therapy) and/ or some medical therapies (anti-thyroid, chemotherapy etc.) (5). Hypercellularity, microfollicular pattern, prominent atypia, and bizarre cells with big-dark nuclei can be seen and may mimic malignancy $(3,5)$. One should be aware of aforementioned cytomorphologic changes in this clinical setting and evaluate FNA in the light of this clinical information.

\section{AMYLOID GOITRE}

Amyloid is an amorphous, dense, acellular material, generally associating MTC in thyroid FNAs. It can be a sign of primary or secondary amyloidosis (amyloid goitre) or can accompany plasmacytomas and MALT lymphomas (23, $24)$. Due to its resemblance to dense colloid, recognizing amyloid on cytology slides may be difficult (Figure 2D). Both amyloid and colloid are seen metachromatic in DiffQuick and blue-green-pink-orange in PAP stains; amyloid looks more solid and hyaline-like than colloid, usually with sharply defined borders, and can always be confirmed by histochemical studies $(13,24)$.
Presence of amyloid may cause inflammation, reactive changes and giant cell reaction leading to an atypical/ suspicious diagnosis (25-27). On the other hand, if it remains unrecognized basically amyloid goitre or a hidden medullary carcinoma within it may be missed. When amyloid is detected in thyroid FNA biopsies, medullary carcinoma should be carefully searched and excluded both by morphology and immunocytochemistry.

\section{INFLAMMATORY LESIONS}

Inflammatory lesions of thyroid mainly include granulomatous thyroiditis and lymphocytic thyroiditis (Hashimoto's thyroiditis). FNA is not indicated in both lesions in any guidelines, unless, accompanied by nodule formation.

\section{A. Granulomatous Thyroiditis}

Granulomatous reaction due to subacute thyroiditis (De Quervain's thyroiditis) is much more common than other granulomatous conditions of thyroid such as fungal infections, tuberculosis or sarcoidosis (28). Numerous neutrophils, mononucleated inflammatory cells are seen in early stage while increased amount of fibrous stromal fragments and abundant multinucleated giant cells mixed with lymphocytes are much prominent in late stage $(29,30)$ (Figure 3A). Presence of well-formed granulomata is quite helpful in the differential diagnosis $(31,32)$. Follicular cells are usually scanty and may show some atypia; in addition epithelioid histiocytes may remain unrecognised and can be interpreted as atypical cells. Then the aspirate with these cells showing prominent hypochromasia, elongation and micronucleoli is a good candidate to be overdiagnosed as PTC. Recognizing the cytomorphologic details of multinucleated giant cells, epithelioid histiocytes, fibroticdegenerated stromal fragments in the busy background created by acute-chronic inflammation and debris, is important to prevent false positive diagnosis in this entity (32-34). Absence of follicular epithelial cells with oncocytic change, presence of particular clinical findings and serological/laboratory tests helps excluding other benign entities in the differential diagnosis.

\section{B. Lymphocytic Thyroiditis}

Hashimoto's thyroiditis is a well-established entity with typical clinical and cytomorphological findings. Polymorphic lymphoid infiltrations, plasma cells, micro-tissue fragments of germinal centre formation, oncocytic changes in the epithelium are typical features (Figure 3B,C).

Pitfalls in the cytological evaluation vary depending on the stage of the disease as well as accompanying Graves' 
disease. "Cellular stage" is composed of proliferation of oncocytes. Oncocytic change leads some nuclear atypia: nuclear enlargement, fine chromatin texture, prominent nuclear membrane and macronucleoli (Figure 3C,D). Nuclear grooves and even pseudoinclusions are described in Hashimoto's thyroiditis $(13,35)$. Not only these changes but also squamous metaplasia of thyroid follicular epithelial cells in "fibrotic stage" may be misleading as suspicious for malignancy. Indeed Hashimoto's thyroiditis is one of the most common causes of false positive PTC diagnosis (3, 36-39). On the other hand, PTC arising in Hashimoto's thyroiditis" is not rare; and a cytomorphologically clear-cut PTC should not be downgraded as 'atypia' or 'suspicious for malignancy' because of the presence thyroiditis in the background (Figure 4A,B). Besides, "Warthin's variant of PTC" should also be remembered and excluded in an aspirate composed of oncocytic cells and lymphocytes. In a study by Harvey et al, it is shown that epithelial groups of Hashimoto's thyroiditis are usually infiltrated by lymphocytes in contrast to the epithelial clusters of PTC which are almost always devoid of lymphocytes (35).

Sampling dominant nodule in Hashimoto's thyroiditis may produce aspirates mainly composed of oncocytes in macrofollicles, microfollicles, trabecula, or solid sheets that could be interpreted as oncocytic follicular neoplasm leading to a redundant lobectomy $(35,40)$ (Figure 4C,D). Careful search for the lymphocytic component in the background is necessary; even if it is lacking, in the appropriate clinical setting Bethesda System recommends to report such cases as "Atypia of undetermined significance/ Follicular lesion

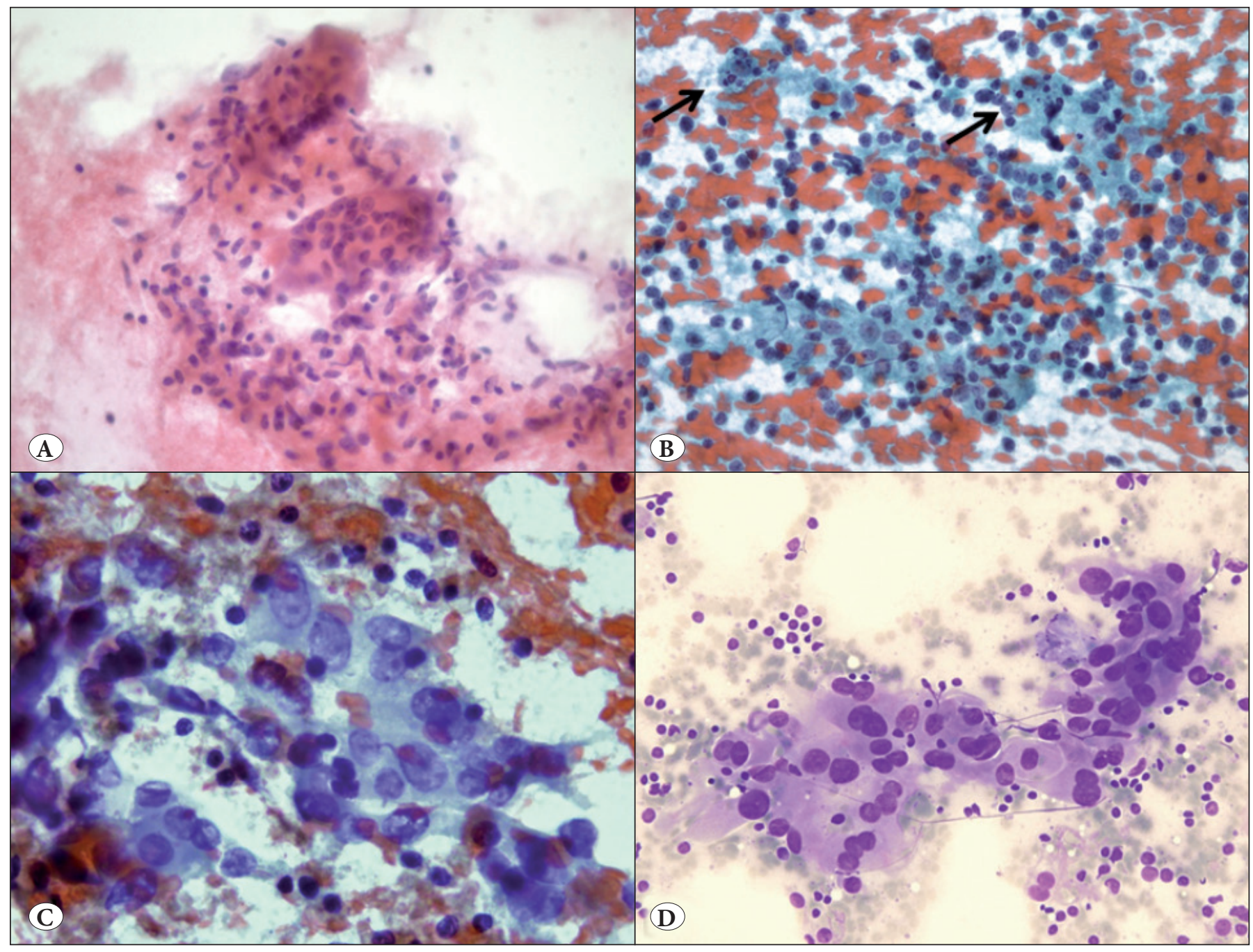

Figure 3: A) Epithelioid histiocytes, lymphocytes and multinucleated giants cells characterizing granulomatous thyroiditis (Pap x400). B) Lymphohistiocytic aggregates with tingible body macrophages (arrows) in lymphocytic thyroiditis (Pap x400). C) A group of oncocytes from Hashimoto's thyroiditis infiltrated by lymphocytes, showing fine chromatin, prominent nucleoli and occasional grooves (Pap x1000). D) Pleomorphism in oncocytic cells of Hashimoto's thyroiditis with large oval nuclei (MGG x400). 
of undetermined significance (AUS/FLUS)" instead of "Follicular neoplasm/Suspicious for follicular neoplasm (FN/SFN)" (41).

Aspirates in "florid lymphoid phase" may be entirely composed of lymphocytes and may be confusing as low grade lymphoma. Detailed clinical findings and multiple passes for flow cytometry would be very useful in this differential diagnosis (42)

\section{FOLLICULAR LESIONS}

The follicular lesions of thyroid basically encompass adenomatous nodule (AN), follicular adenoma (FA), and follicular carcinoma (FC) that can be simply defined by the presence of a capsule (AN vs. FA) and capsular/ vascular invasion (FA vs. FC) on histopathological grounds $(43,44)$.
For these lesions, by definition, cytopathology turns out to be a screening test rather than a diagnostic test. FN/SFN is the category covering these lesions in the Bethesda System for Reporting Thyroid Cytology (TBSRTC) (41). Apart from AN, FA and FC, follicular variant of papillary carcinoma (FV-PTC), poorly differentiated carcinoma, parathyroid adenoma, dyshormonogenetic goitre, thyroiditis are the other entities that could be considered in the differential diagnosis of this category (Figure 5A-D, 6A-D).

When the aspirate is predominantly composed of microfollicles, background and accompanying components should be carefully analysed. Presence of lymphocytes, histiocytes, abundant colloid, cystic changes, stromal fragments, sheets in honeycomb arrangement mostly suggest benign entities,

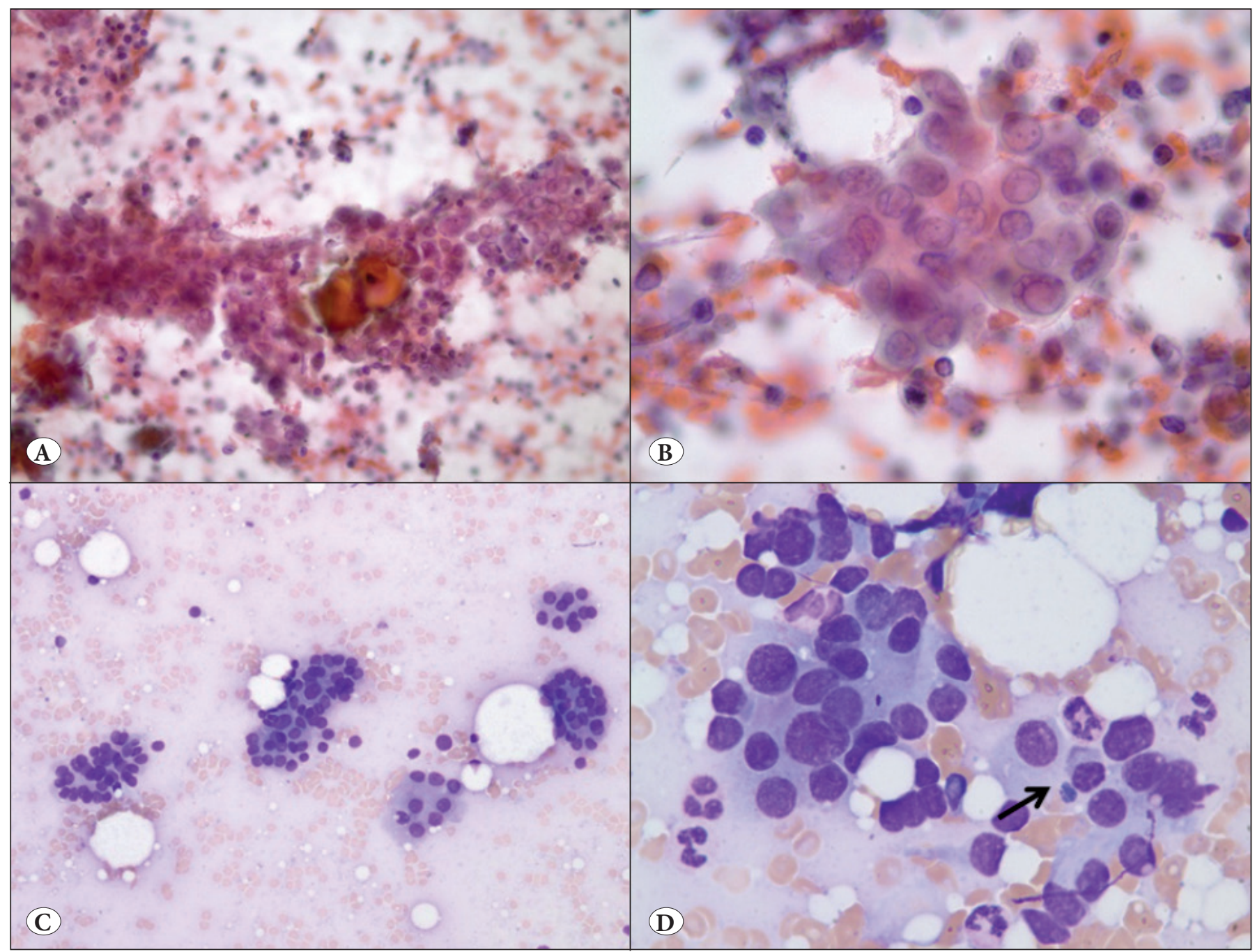

Figure 4: A) Papillary thyroid carcinoma arising in Hashimoto's thyroiditis presenting with many epithelial clusters showing typical nuclear features (Pap x200). B) Clear cut nuclear membrane irregularity with intranuclear pseudoinclusions, chromatin clearing and nuclear grooves (Pap 1000). C, D) Sampling from a dominant nodule of Hashimoto's thyroiditis with many oncocytes showing microfollicular pattern; notice the plasma cell in the background (arrow) (MGG x200, MGG x1000). 
whereas, uniform proliferation of microfollicles with scant colloid indicate neoplasms $(5,13)$.

Even though the definition of follicular lesions on FNA is not clear enough, cellular aspirates with scanty amount of colloid composed of microfollicles in $>50-70 \%$ are evaluated as FN/SFN (41) Microfollicles demonstrate a uniform appearance. Trabeculae, cell crowding and isolated single cells in the background are other characteristics of these lesions $(13,45)$. Cases with colloid in the background showing micro/macrofollicular pattern are not covered by this term even if the aspirate is hypercellular. They should be considered as either benign nodule or pattern atypia (AUS/FLUS in TBSRTC) depending on the amount of colloid, microfollicle ratio and cellularity (41).
Microfollicles are composed of less than 15 overlapping thyroid follicular epithelial cells forming a circle that is at least two-thirds complete with or without intraluminal dense colloid (46). Macrofollicles, form small or large flat sheets/groups or even rows but not circles; overlapping is not their character. Microfollicles can be observed as primary pattern- scattered isolated single microfollicles- or in groups as secondary pattern. One should be careful not to call the crowded small groups in clot as microfollicles; in the bloody smears, clot may create pseudo microfollicular appearance. In that situation, observing microfollicles out of the clot may be helpful (41).

Sampling from microfollicular/cellular areas of benign nodules may always trigger a diagnosis of FN/ SFN and give rise to an unnecessary surgery. However, the main

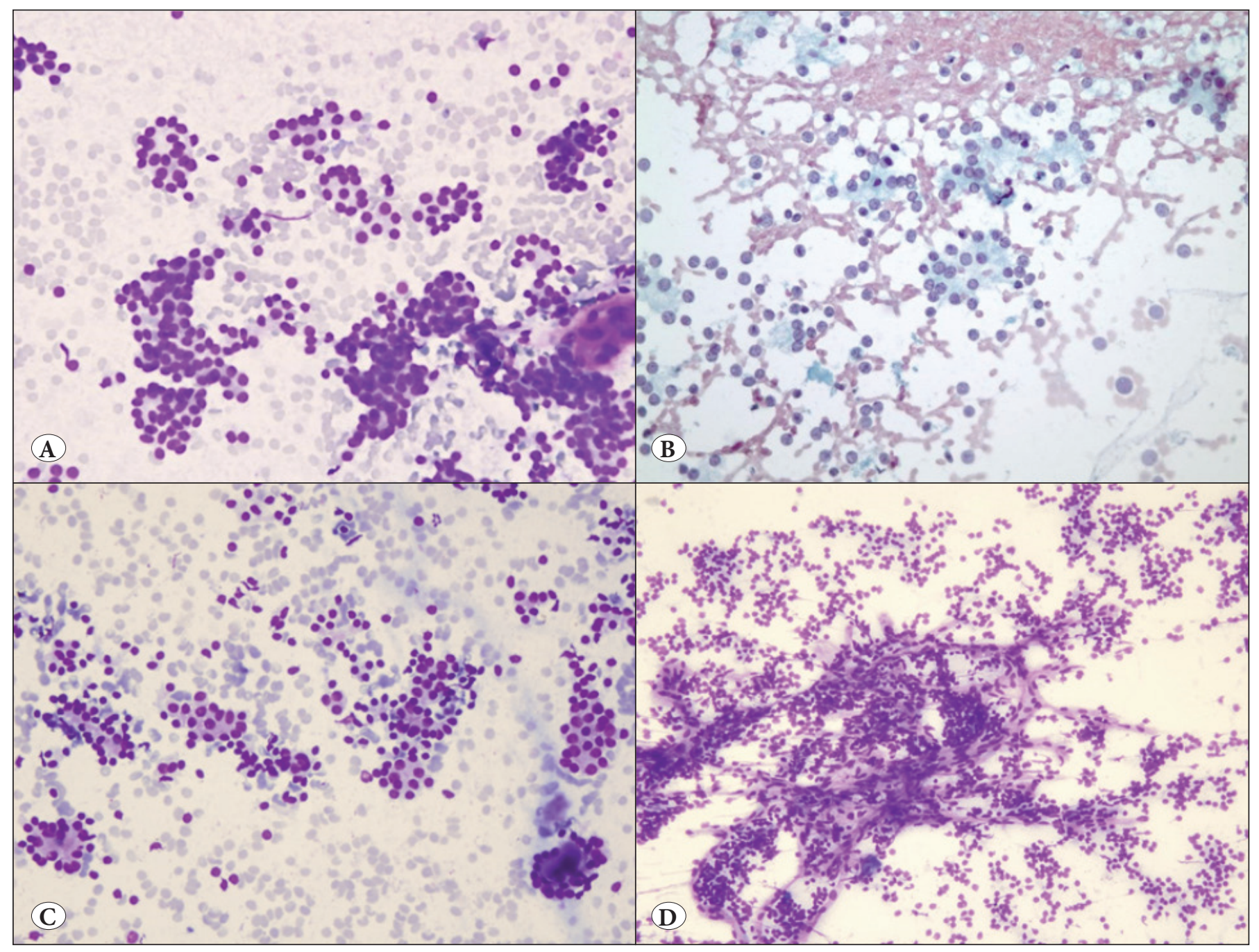

Figure 5: A) Uniform proliferation of microfollicules with scant or no colloid in the background producing a microscopic appearance quite similar to each other from adenomatous nodule (MGG x200), B) Follicular carcinoma (Pap x200), C) Follicular variant of papillary thyroid carcinoma which do not present with classical nuclear features (MGG x200), and D) parathyroid adenoma with a prominent vascular network (MGG x100). 
goal of cytopathology in these lesions is not to set up an absolute diagnosis between those entities but the correct management for the patient. Unfortunately, the specificity of FN/SFN diagnosis for malignancy is poor being around $20 \%(2,45)$.

Cytomorphological features do not allow distinguishing FAs from FCs. Besides the cyto-architecture, many studies have been searching for clinico-pathologic findings/ patients' demographics to increase the specificity, and most of them have suggested to pay attention nodules larger than $3-4 \mathrm{~cm}$ to predict malignancy $(2,45)$.

Follicular variant PTC (FV-PTC) is the biggest trap to be excluded from FN/SFN category (Figure 5C, 6C). The nuclei of follicular lesions/neoplasms are expected to be round and rather hyperchromatic with coarse granular chromatin, which might be slightly larger than regular thyroid follicular epithelial cells. The cases showing nuclear features suspicious for PTC should be reported as "Suspicious for malignancy" regardless of their prominent microfollicular pattern. However, it is well known that some of the FVPTCs do not show the characteristic nuclear features of PTC and present with subtle nuclear changes. So, around $15-20 \%$ of cases diagnosed as FN/SFN turn out to be FVPTC at the end $(13,45)$.

Intrathyroidal parathyroid adenoma and dyshormonogenetic goitre are the other entities that are characterized by microfollicular pattern and lack of colloid. Presence of congenital hypothyroidism for dyshormonogenetic

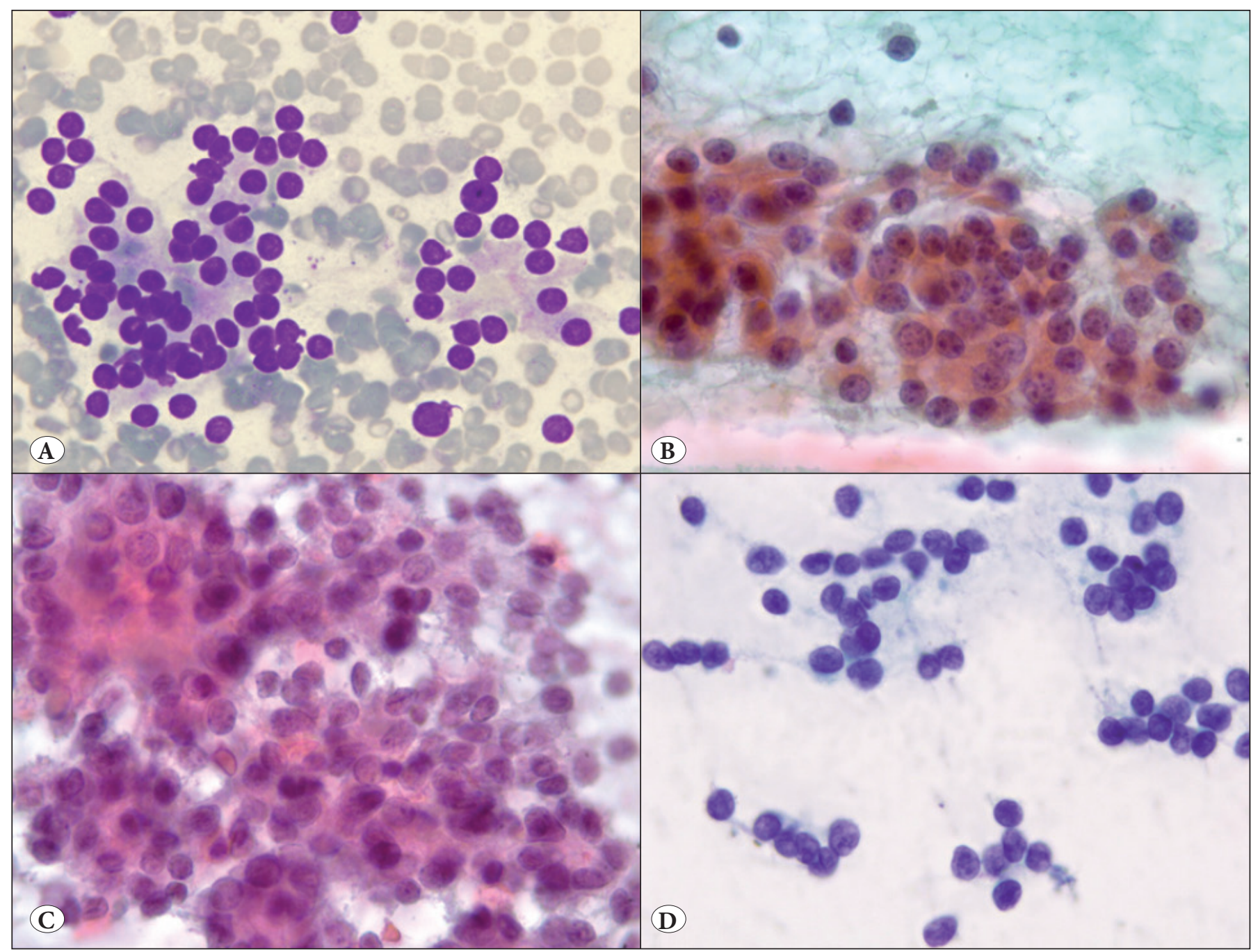

Figure 6: A) Aspirates predominantly composed of microfollicules from different entities; parathyroid adenoma with round uniform nuclei (MGG x1000), B) Dishormonogenetic goiter with empty follicules (MGG x1000), C) Follicular variant of papillary thyroid carcinoma displaying oval nuclei, chromatin clearing, nuclear grooves and overlapping (Pap x1000), D) Poorly differentiated thyroid carcinoma characterized by small cells showing hyperchromasia, some anisokaryosis and nuclear membrane irregularity (MGG x1000). 
goitre, and performing PTH assays on needle rinse or immunohistochemical studies on cell blocks are simple but golden tips in the differential diagnosis. Microfollicules without intrafollicular colloid (empty follicles) is typical for dyshormonegenetic goiter (Figure 6B); anisokaryosis with large bizarre cells is another characteristic feature of this lesion (47). Parathyroid adenomas show a prominent vascular network (Figure 5D) and neuroendocrine type chromatin which is very helpful in the differential diagnosis. Sheets/clusters or microfollicules may dominate in the aspirates; generally many bare nuclei are present in the background; rarely anisokaryosis and occasionally colloid like-parathyroid secretions can be seen (48). Particularly for the aspirates from thyroidectomy beds which show microfollicular pattern, parathyroid tissue should always be remembered in the differential diagnosis (49).

Another entity that should be mentioned here is poorly differentiated thyroid carcinoma. It is an aggressive follicular epithelial derived thyroid malignancy commonly presents with solid/trabecular/insular (with groups surrounded by endothelium) pattern. Naked nuclei in the background are common; microfollicles, may be seen $(50,51)$. The cells are characterized by small nuclei with some convolutions, speckled chromatin, and scant cytoplasm. It lacks nuclear features of PTC. Mitosis, apoptosis, and rarely necrosis can be seen. Rather uniform small cells in a hypercellular, crowded, partially microfollicular aspirate (Figure 6D) frequently cause a misinterpretation as FN/SFN leading to inadequate patient management (51). However, at high magnification nuclear abnormality is clearly present in these tumours as pleomorphism, coarser chromatin and anisokaryosis (50). Due to its nuclear features and chromatin texture, the other major pitfall in the differential diagnosis is MTC $(13,50)$.

When microfollicles dominate on FNA, remembering three " $A$ " could prevent misinterpretations and enables a better clinical management: Be aware oflimits of cytomorphology; be awake for the presence of sheets/macrofollicles, abundant colloid, lymphocytes, obscuring blood; avoid down grading nuclear atypia. However, unfortunately FN/SFN category is the grey zone of thyroid cytology and suffers from intra/ interobserver variability $(2,45,52)$.

\section{ONCOCYTIC LESIONS}

Oncocytic lesions of thyroid present a spectrum from hyperplasia / metaplasia to neoplasia that have always attracted pathologists and cytopathologists by their unique cell morphology $(53,54)$. Oncocytic cells have abundant, finely granular, dense eosinophilic cytoplasm, and centrally placed large round nuclei with prominent nucleoli. Oncocytes and hyperfunctioning thyroid follicular epithelial cells may look similar at first glance, however, oncocytes have beautifully defined cell borders whereas hyperfunctioning thyroid follicular epithelial cells do not (5). Granularity of the cytoplasm is also an important clue that only oncocytes have (Figure 7A,B).

Pitfalls in the diagnosis of oncocytic lesions are quite similar to follicular lesions and may be analysed in three parts; -the differentiation between non-neoplastic and neoplastic lesions, -true oncocytic neoplasia versus oncocytic variant of other thyroid malignancies (Figure 7C,D) and - oncocytic adenoma versus carcinoma which is mostly impossible by cytology. However, in the study of Elliot et al. from 14 designated cytomorphologic features, the following ones endorsed malignancy for oncocytic aspirates; non-macrofollicular architecture, absence of colloid and inflammation, presence of transgressing blood vessels (55). Background colloid, inflammation and also the ratio of oncocytic cells are important to identify nonneoplastic nodules; the aspirates from oncocytic neoplasms are composed of $>70 \%$ oncocytes (56). Differential diagnosis of oncocytic lesions are discussed in more detail in the related topic such as lymphocytic thyroiditis, PTC and MTC.

\section{PAPILLARY THYROID CARCINOMA (PTC)}

PTC is the most common thyroid malignancy. According to the SEER (the US Surveillance, Epidemiology and End Results) program between 2002-2011, thyroid cancer has increased more than any other malignancy including cervix uteri, breast, colon and prostate cancer (57). This trend is mainly explained by the improvement in the diagnostic modalities, widespread use of advanced imaging techniques $(58,59)$. But some questions still remain: Why the other malignancies have not followed the same trend by the increased usage of advanced techniques? Why not only papillary microcarcinomas, but also large cancers and advanced stage thyroid malignancies are increasing? Why there is a striking increase only in PTC, and specifically in FV-PTC $(57,60)$ ?

Based on this epidemiologic truth, the goal of FNA is not to miss those PTCs that are observed today more frequently comparing to past decades. Apart from correctly detecting these tumors, an additional responsibility is to differentiate aggressive variants from non-aggressive variants if possible.

The pitfalls related to the cytological diagnosis of PTC should be analyzed in two parts concerning pattern and nuclear features. It is well known that nuclear details are the 
core of PTC diagnosis: "enlargement, oval shape, membrane irregularity, clearing, longitudinal grooves, intranuclear pseudo-inclusions, overlapping (Figure 8A,B).

Among the nuclear features of PTC, the most specific is intranuclear pseudo inclusions however they are not present in all cases (61). One should be strict to define intranuclear pseudoinclusions, since their presence makes the aspirate at least suspicious for PTC. Intranuclear pseudoinclusions should be large enough and well-delineated with darker outlines to be discriminated from superimposed erythrocytes and artifacts (Figure 2C). Nuclear grooves are almost always present in PTCs, but to be reliable enough they should be widespread and clear rather than being a focal change or an artificial appearance caused by overlapping cells. Hypochromasia/nuclear clearing is an alerting finding, however depending on technical issues it might be misleading on its own. Uniformly enlarged oval shaped nuclei are also important in the diagnosis $(5,13,61$, $62)$.

The patterns of cytologic atypia mimicking PTC as formation of papillae or caps, are nicely described in the literature. Pseudopapillary formation as an architectural pitfall is well emphasized in the study of Majahan et al. $(63,64)$. This study also stated the presence of intranuclear cytoplasmic pseudoinclusions in parathyroid adenomas, thus, parathyroid lesions does not only overlap with FN, but can also mimic PTC on aspirates (63). The pattern of cytologic atypia always needs to be confirmed with nuclear

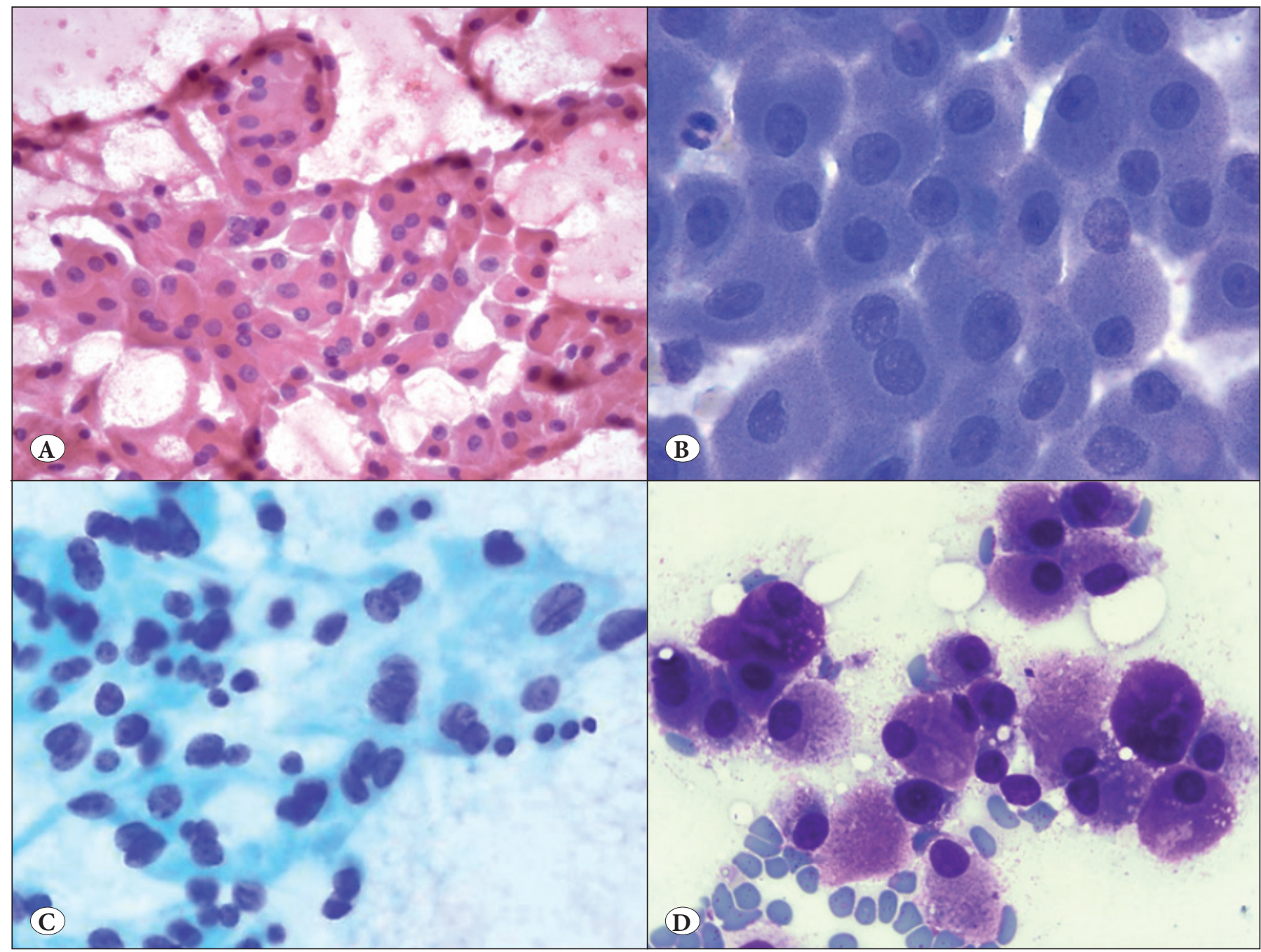

Figure 7: A) Oncocytes with abundant, finely granular cytoplasm, and centrally placed nuclei with macronucleoli from an hyperplastic nodule showing oncocytic metaplasia (Pap x400), and B) Follicular adenoma-oncocytic type (MGG x1000). C) Papillary thyroid carcinoma with oncocytic features showing oval nuclei, pale chromatin and nuclear grooves, (Pap x1000). D) Medullary thyroid carcinoma with large granular cytoplasm but with characteristic eccentric nuclei mimicking oncocytes (MGG x1000). 
atypia for the diagnosis of PTC. However, remembering FVPTC would be hectic after this statement which is shown in the literature with many papers to have less prominent nuclear features compared to classical PTC (65).

Psammoma bodies are quite specific for PTC; however dystrophic calcifications and dense colloid bodies should not be interpreted as psammoma bodies which are almost never seen in laminated appearance in contrast to psammoma bodies. Another point is the amount and type of colloid that is usually scanty and bubble-gum type in PTC. However, stromal degenerative fragments can mimic bubble-gum type colloid and large amounts of loose colloid may also be seen in PTC (13).
Keeping in mind that all the cytological features cannot be present in each case one should be careful not to miss PTC; on the other hand, not to overdiagnose nuclear and/or pattern atypia in benign entities as $\operatorname{PTC}(13,66,67)$. The two categories of the Bethesda System, "atypia of undetermined significance" and "suspicious for malignancy", are present for these equivocal findings and the degree of atypia determines the appropriate choice in reporting (41).

Tall cell variant, columnar cell variant, diffuse sclerosing variant, hobnail variant, solid variant and widely invasive follicular variant are accepted as aggressive variants of PTC (68). If their characteristic features are recognized on FNA should be mentioned in the report.

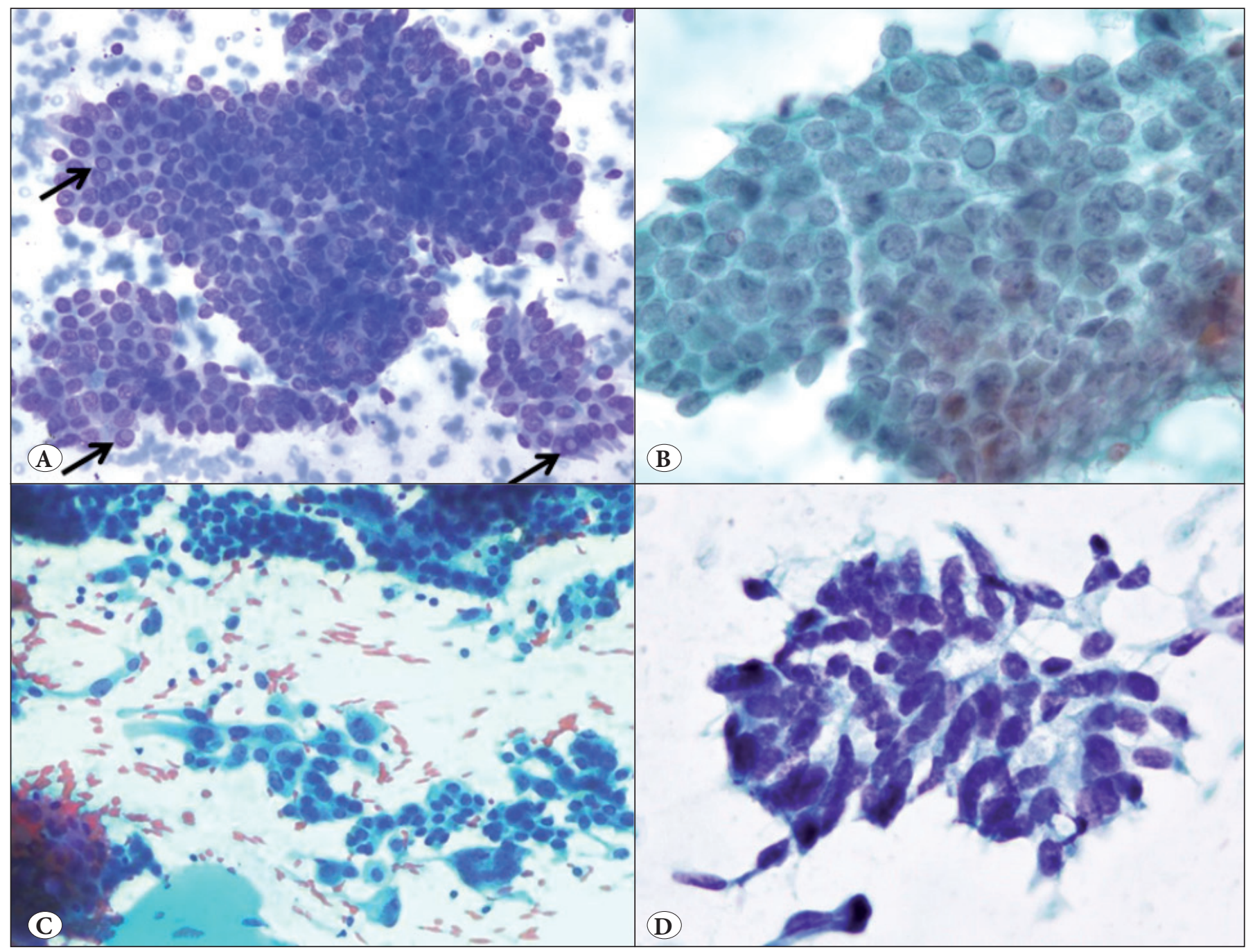

Figure 8: A) Sheets of papillary thyroid carcinoma with nuclear overlapping and frequent nuclear pseudoinclusions (MGG x200). B) Papillary thyroid carcinoma showing typical nuclear features such as oval nuclei, chromatin clearing, nuclear grooves, pseudoinclusions, small marginated nucleoli, and prominent overlapping (Pap x1000). C) Tail-like cells with elongated cytoplasm in tall cell variant of papillary thyroid carcinoma (Pap x200). D) Columnar cell variant of papillary thyroid carcinoma characterized by pseudostratified elongated nuclei without grooves and pseudoinclusions forming rosette like structures (Pap x1000). 
Tall cell variant of PTC presents in cytology by large polygonal or elongated cells with large eccentric nuclei and abundant cytoplasm, prominent grooves, and frequent intranuclear pseudoinclusions (more than one in a single nucleus). Briefly all the features of PTC are exaggerated in these tumors. Lymphocytes can be observed in the background. In some cases "tail-like cells" with elongated cytoplasm and eccentric nuclei can be seen $(50,69)$ (Figure 8C).

Hobnail variant of PTC is characterized by cells with their nuclei located towards the apical portion of the cell. They form micropapillary structures; discohesion may be prominent. Small cells with little cytoplasmic tails like teardrops are typical for this tumor $(50,70)$.

Diffuse sclerosing variant is a challenging entity both by its clinical and cytologic features. It may present like Hashimoto's thyroiditis and may look like thyroiditis on cytology since it is a diffusely infiltrative tumor commonly involving both lobes and characterized by prominent lymphocytic infiltration in the background. However, paying attention to the nuclear features prevents under-diagnosing as thyroiditis. Presence of numerous psammoma bodies, squamous metaplasia and large uniloculated or septated cytoplasmic vacuoles are clues to identify this aggressive variant $(50,71)$.

Another aggressive variant, which could be challenging on cytology is the columnar cell variant. It does not show the typical nuclear features of PTC, and characterized by pseudostratified oval to elongated nuclei with powdery chromatin (Figure 8D). Grooves and pseudoinclusions are uncommon; forms papillae, sheets and rosette-like microfollicles $(50,72)$. Its unique morphology generally allows it to be recognized on FNA; however due to the lack of PTC nuclei, it may be under-diagnosed as follicular neoplasm or diagnosed as malignant but cannot be typed as PTC. It should be distinguished from metastatic carcinomas especially from colonic and endometrioid adenocarcinomas and other thyroid malignancies like medullary carcinoma. Immunohistochemical studies, laboratory and clinical findings are important in the differential diagnosis (72).

MTC is one of the great mimickers of PTC; nuclear elongation, intranuclear pseudoinclusion, groove-like formation, nuclear membrane irregularity are one of those cytomorphologic features that can be seen in both malignancies. However, predominantly dispersed cell population, neuroendocrine type chromatin, some binucleation, eccentric nuclei, presence of both plasmacytoid and spindle cells helps to identify MTC. If in doubt, immunohistochemical studies and/or serum calcitonin analysis will give the final diagnosis (13).
Another primary thyroid tumour, which is almost always misdiagnosed as PTC or suspicious for PTC, is hyalinizing trabecular adenoma (HTA). It may also mimic MTC. Aspirates show oval to spindle-shaped cells with frequent intranuclear pseudoinclusions, in loose groups. Nuclei are uniform with smooth contours, grooves are uncommon. Presence of a metachromatic acellular material surrounded by tumor cells in a radiating fashion is one of the characteristics of this lesion. However, unfortunately this material may be interpreted as amyloid or colloid. Papillary or sheet-like fragments are generally missing ; if suggested in differential diagnosis membranous immunoreactivity for MIB-1 would be very helpful in correct typing of this tumor (73).

\section{MEDULLARY THYROID CARCINOMA (MTC)}

MTC is much more aggressive than follicular derived neoplasms of the thyroid, however unfortunately it could be misdiagnosed as oncocytic follicular neoplasm (OFN) or PTC. It is characterized by many single cells and loose tissue fragments, typically follicular formation is not seen and papillary structures are very rare. However, it may display nested/ trabecular/ loose microfollicular pattern, which could be misleading as follicular neoplasm, and may show oncocytic cytoplasm mimicking OFN. True oncocytes display centrally placed nuclei with macronucleoli which are unusual for MTC $(13,74)$.

It can also mimic PTC in the presence of amyloid resembling thick colloid and intranuclear pseudoinclusions as mentioned above. If totally dispersed cell pattern is seen, could be misinterpreted as lymphoma and plasmocytoma ${ }^{74}$. Plasmacytoid appearance with eccentric nuclei is characteristic of MTC; usually round epithelioid/ plasmacytoid cells are mixed up with elongated spindly cells (Figure 9A,B). If spindle cells predominate, it can always be confused with mesenchymal tumors, regenerative/ degenerative processes (WARD cells) and anaplastic thyroid carcinoma. Occasionally, pleomorphic tumour giant cells can be seen and they may be many in number in giant cell variant of MTC; then major differential diagnosis would be anaplastic thyroid carcinoma $(13,75,76)$ (Figure 9C). Differential diagnosis also includes metastatic neuroendocrine tumors and paraganglioma (Figure 9D). However, distinguishing these entities by cytomorphology alone is nearly impossible, clinical findings and immunohistochemistry is needed (77).

C cell hyperplasia can also nicely mimic MTC, if c-cell hyperplasia forms nodules large enough to be detected by ultrasonography and successfully aspirated, or in a blind aspiration from a patient with elevated serum calcitonin 


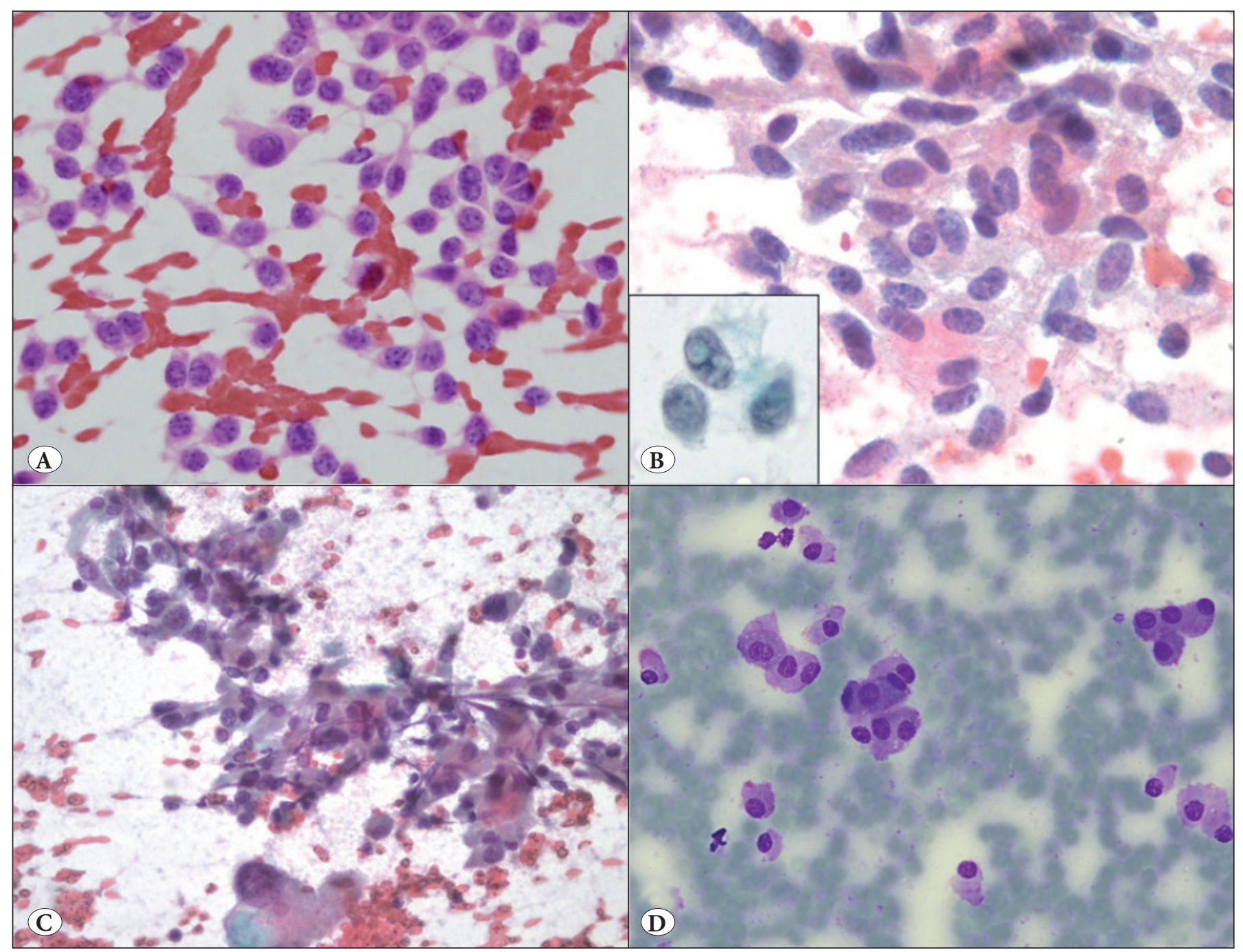

Figure 9: A) Dispersed cells of medullary thyroid carcinoma, plasmacytoid or spindle in shape with coarsely granular chromatin, and tiny cytoplasmic tails (Pap x400). B) Spindle cells and occasional pseudoinclusions (Pap x1000), C) Pleomorphism and tumor giant cells in medullary thyroid carcinoma (Pap x200). D) Metastatic pulmonary carcinoid tumor in thyroid gland mimicking medullary thyroid carcinoma (MGG x400).

level, there is no solution to discriminate c-cell hyperplasia from MTC by cytomorphology alone, still should be remembered as a possibility (78).

\section{RARE TUMORS}

Discussing the pitfalls in the cytological diagnosis of rare tumors of the thyroid gland such as anaplastic carcinoma, lymphoma, CASTLE, etc. is out of our scope in this review. However, they should always be in mind in addition to metastatic malignancies. Even though metastatic malignancies of thyroid are uncommon, it is always a possibility in the presence of a thyroid nodule, especially in patients with known cancer. Any cytomorphology, which is not typical for common primary thyroid tumours, should alert us for this possibility.

\section{CONFLICT OF INTEREST}

The authors have declared no conflict of interest.

\section{REFERENCES}

1. Baloch ZW, Bedrossian C. Following the steps of Abu al-Qasim to Bethesda and beyond: The continuing deliberations in thyroid fine-needle aspiration. Diagn Cytopathol. 2012; 40 Suppl 1:E1-3.

2. Faquin WC. Diagnosis and reporting of follicular-patterned thyroid lesions by fine needle aspiration. Head Neck Pathol. 2009; 3:82-5.

3. Baloch ZW, LiVolsi VA. Current role and value of fine-needle aspiration in nodular goitre. Best Pract Res Clin Endocrinol Metab. 2014; 28:531-44. 
4. Cooper DS, Doherty GM, Haugen BR, Kloos RT, Lee SL, Mandel SJ, Mazzaferri EL, McIver B, Pacini F, Schlumberger M, Sherman SI, Steward DL, Tuttle RM. Revised American Thyroid Association management guidelines for patients with thyroid nodules and differentiated thyroid cancer. Thyroid. 2009; 19:1167-214.

5. De May Richard. The Art and science of cytopathology. 2nd ed. Chicago: ASCP;2012.

6. Ujiki M, Sturgeon C, Nayar R, Angelos P Parathyroid cyst: Often mistaken for a thyroid cyst. World J Surg. 2008; 32:1234.

7. Wei S, LiVolsi VA, Baloch ZW Pathology of thyroglossal duct: An institutional experience. Endocr Pathol. 2015; 26:75-9.

8. Rossi ED, Revelli L, Giustozzi E, Straccia P, Stigliano E, Lombardi CP, Pontecorvi A, Fadda G Large non-functioning parathyroid cysts: Our institutional experience of a rare entity and a possible pitfall in thyroid cytology. Cytopathology. 2015; 26:114-21.

9. Mete O, Asa SL. Pitfalls in the diagnosis of follicular epithelial proliferations of the thyroid. Adv Anat Pathol. 2012; 19: 363-73.

10. Jaragh M, Carydis VB, MacMillan C, Freeman J, Colgan TJ. Predictors of malignancy in thyroid fine-needle aspirates "cyst fluid only" cases: Can potential clues of malignancy be identified? Cancer. 2009; 117:305-10.

11. Faquin WC, Cibas ES, Renshaw AA. "Atypical" cells in fineneedle aspiration biopsy specimens of benign thyroid cysts. Cancer. 2005; 105:71-9.

12. Jaffar R, Mohanty SK, Khan A, Fischer AH. Hemosiderin laden macrophages and hemosiderin within follicular cells distinguish benign follicular lesions from follicular neoplasms. Cytojournal. 2009; 6:3.

13. Ali SZ, Nayar R, Krane JF, Westra WH. Atlas of Thyroid cytopathology with histopathologic correlations. New York:Demos Medical Publishing;2014.

14. Pusztaszeri MP, Krane JF, Cibas ES, Daniels G, Faquin WC. FNAB of benign thyroid nodules with papillary hyperplasia: A cytological and histological evaluation. Cancer Cytopathol. 2014; 122:666-77.

15. LiVolsi VA, Merino MJ. Worrisome histologic alterations following fine-needle aspiration of the thyroid (WHAFFT). Pathol Annu. 1994; 29 ( Pt 2):99-120.

16. Recavarren RA, Houser PM, Yang J Potential pitfalls of needle tract effects on repeat thyroid fine-needle aspiration. Cancer Cytopathol. 2013; 121:155-61.

17. Fadda G, Muie A, Rufini V, Ardito G, Revelli L, Fiorino MC, Capelli A. Cystic medullary thyroid carcinoma: Report of a case with morphological and clinical correlations. Endocr Pathol 2000;11:373-7.

18. Hyrcza MD, Winer D, Mete O. Images in endocrine pathology: Papillary variant of medullary thyroid carcinoma with cystic change. Endocr Pathol. 2015; 26:87-9.

19. Chen YK, Lin CL, Chang YJ, Cheng FT, Peng CL, Sung FC, Cheng $\mathrm{YH}$, Kao CH. Cancer risk in patients with Graves' disease: A nationwide cohort study. Thyroid. 2013; 23:879-84.

20. Anderson SR, Mandel S, LiVolsi VA, Gupta PK, Baloch ZW Can cytomorphology differentiate between benign nodules and tumors arising in Graves' disease? Diagn Cytopathol. 2004;31:647.
21. Baloch ZW, LiVolsi VA. Fine-needle aspiration of the thyroid: Today and tomorrow. Best Pract Res Clin Endocrinol Metab. 2008;22:929-39.

22. Brito JP, Gionfriddo M, Morris JC, Montori VM. Overdiagnosis of thyroid cancer and graves' disease. Thyroid. 2014; 24:402-3.

23. Villa F, Dionigi G, Tanda ML, Rovera F, Boni L. Amyloid goiter. Int J Surg. 2008;6 Suppl 1:S16-8.

24. Nobuoka Y, Hirokawa M, Kuma S, Takagi N, Higuchi M, Masuoka H, Miya A, Kubota S, Miyauchi A Cytologic findings and differential diagnoses of primary thyroid MALT lymphoma with striking plasma cell differentiation and amyloid deposition. Diagn Cytopathol. 2014; 42:73-7.

25. Hamed G, Heffess CS, Shmookler BM, Wenig BM. Amyloid goiter. A clinicopathologic study of 14 cases and review of the literature Am J Clin Pathol 1995; 104:306-12.

26. Michael CW, Naylor B. Amyloid in cytologic specimens. Differential diagnosis and diagnostic pitfalls. Acta Cytol. 1999; 43:746-55.

27. Ozdemir BH, Uyar P, Ozdemir FN Diagnosing amyloid goitre with thyroid aspiration biopsy. Cytopathology. 2006;262-6.

28. Shabb NS, Salti I Subacute thyroiditis: Fine-needle aspiration cytology of 14 cases presenting with thyroid nodules. Diagn Cytopathol. 2006;34:18-23.

29. Nikiforov EY. Diagnostic pathology and molecular genetics of the thyroid. 2nd ed. Philadelphia: Lipincott;2012.

30. Mordes DA, Brachtel EF. Cytopathology of subacute thyroiditis. Diagn Cytopathol. 2012;40:433-4.

31. Schwartz LE, Griffin AC, Baloch Z Cell block interpretation is helpful in the diagnosis of granulomas on cytology. Diagn Cytopathol. 2012; 40:939-40.

32. Garcia Solano J, Gimenez Bascunana A, Sola Perez J, Campos Fernandez J, Martinez Parra D, Sanchez Sanchez C, Montalban Romero S, Perez-Guillermo M. Fine-needle aspiration of subacute granulomatous thyroiditis (De Quervain's thyroiditis): A clinico-cytologic review of 36 cases. Diagn Cytopathol. 1997; 16: 214220

33. Shabb NS, Tawil A, Gergeos F, Saleh M, Azar S Multinucleated giant cells in fine-needle aspiration of thyroid nodules: Their diagnostic significance. Diagn Cytopathol. 1999;21:307-12.

34. Hoang TD, Mai VQ, Clyde PW, Shakir MK. Simultaneous occurrence of subacute thyroiditis and Graves' disease. Thyroid. $2011 ; 21: 1397-400$.

35. Harvey AM, Truong LD, Mody DR. Diagnostic pitfalls of Hashimoto's/lymphocytic thyroiditis on fine-needle aspirations and strategies to avoid overdiagnosis. Acta Cytol. 2012; 56:35260.

36. Junik R, Juraniec O, Pypkowski J, Krymer A, Marszalek A. A difficult diagnosis: A case report of combined Riedel's disease and fibrosing Hashimoto's thyroiditis. Endokrynol Pol. 2011 62:351-6.

37. Ylagan LR, Farkas T, Dehner LP Fine needle aspiration of the thyroid: A cytohistologic correlation and study of discrepant cases. Thyroid. 2004; 14:35-41.

38. Kollur SM, El Sayed S, El Hag IA. Follicular thyroid lesions coexisting with Hashimoto's thyroiditis: Incidence and possible sources of diagnostic errors. Diagn Cytopathol. 2003; 28:35-8. 
39. MacDonald L, Yazdi HM. Fine needle aspiration biopsy of Hashimoto's thyroiditis. Sources of diagnostic error. Acta Cytol. 1999; 43:400-6.

40. Chandanwale SS, Kulkarni TV, Patel RJ, Thakkar. A focal nodular Hurthle cell hyperplasia in Hashimoto's thyroiditis: A diagnostic dilemma on fine needle aspiration. J Cytol. 2014; 31:236-8.

41. The Bethesda System for reporting thyroid cytopathology. Syed AZ, Cibas ES, editors. New York: Springer;2010.

42. Stacchini A, Pacchioni D, Demurtas A, Aliberti S, Cassenti A, Isolato G, Gazzera C, Veltri A, Sapino A, Papotti M, Freddi M, Palestini N, Sisto G, Novero D. Utilility of flow cytometry as ancillary study to improve the cytologic diagnosis of thyroid lymphomas. Cytometry B Clin Cytom. November 2014. (Epub ahead of print)

43. Baloch ZW, LiVolsi VA. Follicular-patterned afflictions of the thyroid gland: Reappraisal of the most discussed entity in endocrine pathology. Endocr Pathol. 2014; 25:12-20.

44. Baloch ZW, LiVolsi VA. Our approach to follicular-patterned lesions of the thyroid. J Clin Pathol. 2007; 60: 244-50.

45. Baloch ZW, Fleisher S, LiVolsi VA, Gupta PK. Diagnosis of "follicular neoplasm": A gray zone in thyroid fine-needle aspiration cytology. Diagn Cytopathol. 2002 ; 26: 41-4.

46. Renshaw AA, Wang E, Wilbur D, Hughes JH, Haja J, Henry MR. Interobserver agreement on microfollicules in thyroid fine needle aspirates. Arch Pathol Lab Med. 2006; 130(2): 148-52.

47. Deshpande AH, Bobhate SK. Cytological features of dyshormonogenetic goiter: Case report and review of the literature. Diagn Cytopathol. 2005; 33:252-4.

48. Agarwal AM, Bentz JS, Hungerford R, Abraham D Parathyroid fine-needle aspiration cytology in the evaluation of parathyroid adenoma: Cytologic findings from 53 patients. Diagn Cytopathol. 2009;37:407-10.

49. Bishop JA, Owens CL, Shum CH, Ali S. Thyroid bed fine-needle aspiration: Experience at a large tertiary care center. Am J Clin Pathol. 2010; 134:335-9.

50. Lastra RR, LiVolsi VA, Baloch ZW. Aggressive variants of follicular cell-derived thyroid carcinomas: A cytopathologist's perspective. Cancer Cytopathol. 2014; 122:484-503.

51. Bongiovanni M, Bloom L, Krane JF, Baloch ZW, Powers CN, Hintermann S, Pache JC, Faquin WC. Cytomorphologic features of poorly differentiated thyroid carcinoma: A multi-institutional analysis of 40 cases. Cancer. 2009; 117:185-94.

52. Cohen DS, VandeGriend ZP, Yoo GH, Folbe AJ, Lin HS. Risk stratification based on thyroid cytology: Can we rely on national data? Am J Otolaryngol. 2014; 35(3):362-5.

53. Asa SL My approach to oncocytic tumours of the thyroid. J Clin Pathol. 2004;57:225-32.

54. Maximo V, Rios E, Sobrinho-Simoes M. Oncocytic lesions of the thyroid, kidney, salivary glands, adrenal cortex, and parathyroid glands. Int J Surg Pathol. 2014; 22:33-6.

55. Elliott DD, Pitman MB, Bloom L, Faquin W. Fine-needle aspiration biopsy of Hurthle cell lesions of the thyroid gland: A cytomorphologic study of 139 cases with statistical analysis. Cancer. 2006; 108:102-9.
56. Montone KT, Baloch ZW, LiVolsi VA. The thyroid Hürthle (oncocytic) cell and its associated pathologic conditions: A surgical pathology and cytopathology review. Arch Pathol Lab Med. 2008;132:1241-50.

57. Ito Y, Nikiforov YE, Schlumberger M, Vigneri R. Increasing incidence of thyroid cancer: Controversies explored. Nat Rev Endocrinol. 2013; 9:178-84.

58. Vigneri R, Malandrino P, Vigneri P The changing epidemiology of thyroid cancer: Why is incidence increasing? Curr Opin Oncol. $2015 ; 27: 1-7$

59. Tufano RP, Noureldine SI, Angelos P. Incidental thyroid nodules and thyroid cancer: Considerations before determining management. AMA Otolaryngol Head Neck Surg. 2015;141:56672.

60. Ito Y, Nikiforov YE, Schlumberger M, Vigneri R. Increasing incidence of thyroid cancer: Controversies explored. Nat Rev Endocrinol. 2013; 9:178-84.

61. Das DK, Sharma PN. Diagnosis of papillary thyroid carcinoma in fine needle aspiration smears: Factors that affect decision making. Acta Cytol. 2009; 53:497-506.

62. Das DK, Mallik MK, Sharma P, Sheikh ZA, Mathew PA, Sheikh M, Mirza K, Madda JP, Francis IM, Junaid TA. Papillary thyroid carcinoma and its variants in fine needle aspiration smears. A cytomorphologic study with special reference to tall cell variant. Acta Cytol. 2004; 48:325-36.

63. Mahajan A, Lin X, Nayar R. Thyroid Bethesda reporting category, 'suspicious for papillary thyroid carcinoma', pitfalls and clues to optimize the use of this category. Cytopathology. 2013; 24:85-91.

64. Khayyata S, Barroeta JE, LiVolsi VA, Baloch ZW. Papillary hyperplastic nodule: Pitfall in the cytopathologic diagnosis of papillary thyroid carcinoma. Endocr Pract. 2008; 14: 863-8.

65. Elsheikh TM, Asa SL, Chan JK, DeLellis RA, Heffess CS, LiVolsi $\mathrm{VA}$, Wenig BM. Interobserver and intraobserver variation among experts in the diagnosis of thyroid follicular lesions with borderline nuclear features of papillary carcinoma. Am J Clin Pathol. 2008; 130: 736-44.

66. Nassar A, Gupta P, LiVolsi VA, Baloch Z Histiocytic aggregates in benign nodular goiters mimicking cytologic features of papillary thyroid carcinoma (PTC). Diagn Cytopathol. 2003;29:243-5.

67. Renshaw AA Fine-needle aspirations of papillary carcinoma with oncocytic features: An expanded cytologic and histologic profile. Cancer Cytopathol. 2011; 119:247-53.

68. Baloch Z, LiVolsi VA, Tondon R. Aggressive variants of follicular cell derived thyroid carcinoma; The so called 'real thyroid carcinomas. J Clin Pathol. 2013; 66:733-43.

69. Bocklage T, DiTomasso JP, Ramzy I, Ostrowski ML. Tall cell variant of papillary thyroid carcinoma: Cytologic features and differential diagnostic considerations. Diagn Cytopathol. 1997; 17:25-9.

70. Asioli S, Maletta F, Pagni F, Pacchioni D, Vanzati A, Mariani S, Palestini N, Lloyd RV, Sapino A Cytomorphologic and molecular features of hobnail variant of papillary thyroid carcinoma: Case series and literature review. Diagn Cytopathol. 2014;42:78-84. 
71. Takagi N, Hirokawa M, Nobuoka Y, Higuchi M, Kuma S, Miyauchi A Diffuse sclerosing variant of papillary thyroid carcinoma: A study of fine needle aspiration cytology in 20 patients. Cytopathology. 2014; 25:199-204.

72. Jayaram G. Cytology of columnar-cell variant of papillary thyroid carcinoma. Diagn Cytopathol. 2000; 22:227-9.

73. Kim T, Oh YL, Kim KM, Shin JH. Diagnostic dilemmas of hyalinizing trabecular tumours on fine needle aspiration cytology: A study of seven cases with BRAF mutation analysis. Cytopathology. 2011; 22:407-13.

74. Chetty R. Hurthle cell medullary carcinomas of the thyroid gland. S Afr J Surg. 1990; 28:95-7.

75. Samulski TD, Livolsi VA, Montone K, Baloch Z The variable pathologic presentations of medullary and micro-medullary thyroid carcinoma: An institutional experience. Pathol Res Pract. 2014; 210:182-5.
76. Kaushal S, Iyer VK, Mathur SR, Ray R. Fine needle aspiration cytology of medullary carcinoma of the thyroid with a focus on rare variants: A review of 78 cases. Cytopathology. 2011; 22: 95105.

77. Sivrikoz E, Ozbey NC, Kaya B, Erbil Y, Kaya S, Yilmazbayhan D, Firat P, Kapran Y Neuroendocrine tumors presenting with thyroid gland metastasis: A case series. J Med Case Rep. 2012;6:73.

78. Aulicino MR, Szporn AH, Dembitzer R, Mechanick J, Batheja $\mathrm{N}$, Bleiweiss IJ, Burstein DE Cytologic findings in the differential diagnosis of C-cell hyperplasia and medullary carcinoma by fine needle aspiration. A case report Acta Cytol. 1998;42:963-7. 